Научная статья

УДК 130.121

DOI: 10.18101/1994-0866-2021-4-53-61

\title{
ФЕНОМЕНОЛОГИЧЕСКИЙ РЕСУРС РУССКОГО СЛОВА «ПОСТУПОК»
}

\section{(C) Ильина Ольга Игоревна}

кандидат философских наук, доцент Департамента психологии и образования

Дальневосточный федеральный университет

Россия, 690000, г. Владивосток, пер. Аякс 10, olilyina@bk.ru

\begin{abstract}
Аннотация. В статье представлен анализ самобытности русского слова «поступок» на основе значений, выявленных в логике трихотомичной модели слова П. Флоренского и зафиксированных в текстах славянских словарей и материалах для словаря древнерусского языка И. И. Срезневского. Данный методологический маневр позволил аргументировать положение, что онтологическое основание поступка нужно искать в «ступе» - ограниченности и неполноте момента, бытия, сознания, которые одновременно хранят в себе необходимость снять эти ограничения; артикулировать положение, что феноменологический ресурс славянского слова «поступок» нужно искать не в иностранных концепциях (И. Канта, Аристотеля и др.), посвященных его аналогу, а в концепциях носителей языка (М. М. Бахтина, В. Н. Сагатовского и др.), и на основе феноменологических процедур, вскрывающих его содержание, структуру, принципиальную незавершенность сути; указать на перспективы феноменологических штудий в области философии поступка как противостоящих диктату философии теорий и языка, если будут учтены и смысловое содержание феномена поступка, хранящееся в слове, и идея о модификации многоуровневости бытия человека в поступке.
\end{abstract}

Ключевые слова: поступок, самобытность, слово, смысловое содержание, со-бытие, многоуровневость, онтологическое основание, феномен, феноменологические процедуры.

\section{Для цитирования}

Ильина О. И. Феноменологический ресурс русского слова «поступок» // Вестник Бурятского государственного университета. Философия. 2021. Вып. 4. С. 53-61.

Исследование поступка методами философского дискурса, раскрывающих и удерживающих его феномен в горизонте возможностей философствующего сознания, есть отклик на методологические противоречия в современных интеллектуальных настроениях. Первое противоречие - это методологическое противостояние между философией языка и философией опыта. «Прозрения», что нарративы правят миром, а языковые игры признаны единственной доступной реальностью (А. Бадью, Г. Гадамер, Р. Рорти и др.) оборачиваются стремлением снять диктат теорий и языка над субъектом и опытом (Ф. Анкерсмит и др.), разоблачить примат мира теоретического над миром живым (М. М. Бахтин) и пр.

Второе противоречие, выходящее за рамки философских наук, связано с языковыми инновациями и экспансией идей, теснящих самобытный дух национальных культур. Импорт мироощущений и мировоззрений проявляется всей многоликостью другости в оппозиции Я-Другой: свой-чужой-иной. В России такой 
поворот, как правило, поддерживается установками собственной интеллектуальной элиты: у них там лучше, прогрессивнее, интереснее, результативнее, современнее; или что касается философии: «их философия более философская» или «западная философская мысль превосходит русскую философскую мысль» и пр. Bce это провоцирует возражения: западная философия - это форма интуиции и медитации западной цивилизации; ее методы видения истин отточены на прогнозах проблем собственной самобытности. Не отрицая близость к западной цивилизации и высокому качеству ее методов, нужно помнить, что чрезмерная готовность к ассимиляции западных идей может обернуться зачисткой собственных методов восхождения к истине и утратой способов глубинного узнавания собственной самобытности, замещением правды, хранящейся в живом слове родного языка, интеллектуальными химерами и пр.

Третье противоречие вытекает из предыдущих и связано с естьностью в языке таких слов, которые указывают на феномены, снимающие методологические противоречия между философией языка и философией опыта (например, таких как «глас Божий» или «лепота»); имеют силу фиксировать феномены онтические по содержанию и онтологические по условиям возможности; не утрачивают свою актуальность в контексте современных исторических событий; способны удерживать топику, где язык, опыт и бытие еще тождественны друг другу. Такие слова в силу своей предельности становятся краеугольными моментами для всевозможных философских сюжетов. Они не могут быть определены как термины и понятия, так как указывают на нечто иное; они делают язык живым самобытным (само-бытие) и со-бытийным, удерживающим принадлежность к событию и бытию. Иногда необходимость в таких словах компенсируется их изобретением, например, у М. Хайдеггера [постов, наличность и пр.] или у постмодернистов [симулякр, след, ризома и пр.]

В русском языке есть слова, фиксирующие логос и бесконечность, бога и человека, бесконечное в конечном, истину в конкретной данности, онтологическое и онтическое как одно и в одном: соборность, поступок, правда, достоинство, лепота и др.; готовые создать современные интеллектуальные интенции, способные потеснить современные господствующие нарративы. Конечно, можно возразить: с одной стороны, каждое слово в любом языке можно распаковать до его основ: от физики к метафизике и далее, если есть к тому способности; или с другой - современность требует новых подходов для ее осмысления, а, значит, выхода за пределы уже существующих логосов, языков и пр. Такие возражения не умоляют заданной темы рассуждения, наоборот, подчеркивают наличие проблемного поля для смежных исследований. Распаковка сакрального ресурса родного языка - того, что уже есть и как след в бытии, и как ключ к действительным событиям, может статься очень современной.

Итак, наша задача - сфокусироваться на мысли о живых словах языка как о произведениях культуры; показать, что слово не всегда тюрьма для опыта и мысли, так как может служить источником «возвышенного исторического опыта» (концептуально отрефлексированного Ф. Анкерсмитом). Констатируя наличие пропасти между философией языка и философией опыта, Ф. Анкерсмит отмечает особый статус живого слова (такого как «Ангел Господень»), провоцирующего 
возвышенный опыт, и резюмирует, что «в любом слове или понятии спрятан ключ к секретам реальности» [1].

Пилотный контент-анализ нескольких словарных статей славянских языков, в которых слово поступок присутствует фонетически и морфологически позволяет нащупать место для интуитивного схватывания поступка как феномена. Словарные статьи сербско-хорватско-русского ${ }^{1}$, чешско-русского ${ }^{2}$ и польско-русского ${ }^{3}$ языков указывают, что морфема и фонема «поступ» ок собирает такие свои значения, как прогресс, продвижение, образ действий, отномение, способ, метод и пр. А накладывая как веер одни значения на другие и раздвигая их по собственному умонастроению, можно получать различные сочетания значений: способ продвижения, способ вести себя, прогрессивный ход, метод обращаться (какимлибо образом с чем-либо) и т. д.

Анализ однокоренных слов древнерусского языка раскрывает содержательную глубину хранящуюся в слове «поступок», и позволяет принять гипотезу о том, что-есть-как основание поступка в бытие. Начнем с того, что слово «сто̆па», которое является и корнем слова поступок, в старорусском языке обозначает не только сосуд для толчения или ступу, но и петлю, западню, капкан, яму, то есть нечто, что ограничивает свободу, ловит и удерживает в определенных границах, пленит. Немного иные значения несут другие однокоренные слова: «сто̆панию» походка, поступать, стремление; «сто̆пати» - ходить, ступать, вступать, «сто̆пити» — ступить, сдвинуть с места; «сто̆пъ» — стычка; «сто̆питика» — сойтись, сразиться [6, стб. 577-578].

Основной посыл сто̆п - удержание; вступление в нечто, удерживающее (обстоятельства, события), где удерживающее может принимать разные формы: сражения, стремления, ловушки и пр.

Появляется смысл придержать предположение, что онтологическое основание поступка - в стуле - ограниченности бытия, которое одномоментно хранит в себе необходимость снять эти ограничения, то есть возможность существования поступка как феномена и как слова, схватывающего этот феномен, хранится в ограниченности и неполноте момента, бытия, сознания.

В древнерусском языке нет слова поступ-ок, точнее, слова с интересующим нас корнем и приставкой есть, а существительное с суффиксом -ок как более позднее изобретение языка отсутствует. Однако те слова, которые ближе всего к

1 «по́ступ||ак, ак 1) поступок; 2) образ действий; поведение; отношение; 3 ) процедура, процесс; метод; 4) юр. делопроизводство; ...»; «по́ступ||ан, ннй, на, нно 1) ступенчатый; 2) постепенный.» «посту́пати.... 1) идти; шагать; ступать; 2) поступать; действовать.» «по́ступно нареч. постепенно, по очереди.» [5, с. 428].

2 «Postup, 1. продвижение, 2. ход, движение, .... 3. прогресс, 4. процесс, 5. повышение»; «Postup $\|$ nê нареч. постепенно, ný 1. постепенный, последовательный, 2. поступатель-ный; ny ovat несов. 1. в прям.и перен. продвигатья; 2. переходить из класса в класс...; 3. поступать; správnê ovat поступать правильно...» [8, с. 403].

3 «Postep, u 1. прогресс; движение вперед...»; «Postep $\|$ ek, ky 1. поступок, действие; 2. уст. способ, образ действия»; «Рostep $\|$ ować, несов. 1. продвигаться, двигаться, идти (вперед), следовать (за кем-то); 2. перен. продвигаться, прогрессировать...; 3. поступать, вести себя, действовать, обращаться (каким-либо образом с чем-либо с чемлибо)...» [12, с. 738]. 
нему по морфологическим и фонетическим признакам, передают значения, указывающие на состояние движения: «посто̆пати» — двигаться, идти, продвигаться вперед; переходить, передаваться, отступать, уступать; «посто̆пити» - сдвинуться с места; пойти, двинуться; приблизиться; устремиться, броситься; выступить, напасть; переправиться; побороть, пересилить; нарушить, отменить; обойти, обмануть; «посто̆пъ» -движение, действие, деяние; «посто̆пъный» - изменяющейся, движущийся [7, стб. 1269-1270].

Если корень «-ступ-» удерживает ступающего в определенных границах, то приставка «по-» дает поступающему свободу: двинуться с места, побороться, пересилить, нарушить и пр. Вероятно, со временем появляется коммуникативная потребность в способе фиксации того, что уже осуществилось, что некое действие-движение завершилось и как следствие рождается новое слово - существительное с суффиксом «-ок», которое позволяет фиксировать действа и события как свершившиеся или завершенные целостности.

В словаре древнерусского языка, созданного усилиями И. И. Срезневского и его учеников, приводятся соответствующие тексты из авторитетных произведений древнерусской письменности. В частности, слово «посто̆пъный» сопровождается любопытной для нашей темы иллюстрацией: «Божество непоступьно, непоступомь все поступьно творњ (божество неподвижное и своею неподвижностью все движущее). Іо. екз. Бог. 35» [7, стб. 1270]. Все тварное обречено быть «посто̆пьным»: быть поступным - значит изменяться, быть движущимся. И, конечно, человеческое существо как сотворенное по образу и подобию Бога обречено быть поступным («посто̆пъным») в соответствии с Богу угодным предназначением (надобностью). А значит, что-то в его поступати («посто̆пати») и поступити («посто̆пити») совершается особым способом, недоступным усилиям других тварей. Отсюда попытка узаконить (для дальнейших исследований) словосочетания: «человек-поступающий» и «человек поступка». Это узаконивание принципиально, так как человеческое существо (человек) - это совершенно отличительная топика в бытие, не сводима к его концептуальным производным (субъект, личность, индивид, индивидуальность); эта топика удерживает многоуровневость человеческого бытия и поступка как способа модификации всех уровней бытия и сознания в их единстве и целостности.

Связь слова с духом народа (В. Гумбольд, Х. Штейнталь, В. Вундт А. А. Потебня, Г. Г. Шпет, П. А. Флоренский, В. В. Виноградов и др.) делает его методологически и методически привлекательным для различных областей познания. В частности, отношение к слову как «методу концентрации», собирающему «в один фокус историческую волю целого народа» [9, с. 263], рассмотренное П. Флоренским, позволяет сделать тоньше и глубже собственную мысль, быть внимательнее к ее выражению. Рассуждая о синергии слова, он набрасывает алгоритм анализа слов в логике «трихотомичного» строения, состоящего из морфемы, фонемы и семемы, и для наглядности предлагает представить фонему «как основное ядро, или косточку, обвернутую в морфему, на которой в свой черед держится семема» [9, с. 234]. Каждое слово, следуя логике троичной модели, состоит из звука, понятия, идеи, порожденных соответствующими тремя духовными функциями: чувственностью, рассудком и разумом (телом, душой и духом). 
Оживим процедуру анализа слова, описанную П. Флоренским: используем фонему слов «посто̆пати», «посто̆пити», «поступок» как ощущение и первое впечатление или чувственное восприятие. И тогда в звуке слова как бы застыл звук шагов («топ», «ступ», «по-ступ») или колотушки в ступе. Этот звук, порожденный прямой экстатичностью, в логике процедуры П. Флоренского начинает символизировать морфему, суть которой оставаться духовной реакцией на ощущение. Морфема - это результат деятельности рассудка, она несет на себе груз представлений и понятий. Понятие слова «поступок» прекрасно отражается в различных словарях. Но морфема еще и символ семемы - идеи слова, которую следует принимать как результат деятельности разума, как духовную реакцию на понятие-представление. И здесь важно следующее: идея, которая хранится русским словом поступок, не должна вытесняться идеями из иностранных текстов: например, идеей слова поступок (нем. handlung) как формы реализации нравственного или гипотетического императивов, разработанной И. Кантом. Скорее русское слово хранит идею нравственного бытия или «не-алиби в бытие» как это показал М. М. Бахтин [2]. Тем более феноменологическая глубина и многоликость русского слова поступок не должны редуцировать к англоязычным (act, action, deed, move, step, etc.) или французским (las acte, la conduite, la démarche, le trait, etc.) аналогам, не удерживающим идеи славянского слова, явившейся схроном философии поступка.

Смысловые значения, которые группируются вокруг корня -стуn- наполняют многогранным содержанием и слово «поступок»: тут и момент собственного движения ступать, и его индивидуальная манера - поступь; и ступени, делающие возможными спуск и восхождение; и стопа, оставляющая следы; и ступа, узнаваемая и как сосуд, в котором перетираются твердые фракции (граница разрушения границ), и средство перемещения в пространстве мистического персонажа - Бабы-яги, тут и совпадающее по звучанию санскритское слово ступа [санскр. स्तूप, stūpa (IAST)], обозначающее один из символов буддийского учения и просветления. Разные возможности ступающего фиксируют различные приставки для слов, имеющих один корень со словом «поступок»: про-ступок, преступать, $y$-ступать и пр., а сама приставка по- как будто утверждает направление становления человеческого существа - по ступеням человеческого бытия.

В современной отечественной философии понимание поступка как многоуровневого и многопланового события удерживается как минимум тремя посылками:

- отношением к поступку не как акту и факту, а как к со-бытию, в котором у человека есть со-автор - бытие: «не-алиби в бытие» М. М. Бахтина [2], «не противо-бытие, но со-бытие» В. Н. Сагатовского [4], «событие с неясным концом» М. Н. Эпштейна [10];

- тезисами о многоуровневости и многоплановости человеческого бытия С. Л. Рубинштейна [3] и полноте бытия человека в поступке М. М. Бахтина [2], позволяющими утверждать, что вся многоуровневость и многоплановость человеческого существа доступна в поступке;

- пониманием целостности поступка, закрепленным в языковой форме словосочетанием «поступок человека», которое косвенно указывает на целостность и единство всех уровней репрезентации (субъект, индивид и пр.) 
У автора данного текста есть свои предпочтения и свое видение многоуровневой правды поступка все они сосредоточены вокруг идеи «размыкания и установки собственных границ». Такая идея позволит говорить о поступке: как о форме модификации индивидуального сознания и индивидуального бытия; как о событии испытания абсолютным духом индивидуального сознания; как об эффекте превышения индивидуальных свойств; как о приращении индивидуального бытия; как о событии творчества духа в границах индивидуального существования и пр.

Нужно признать, что проблема актуальности философии поступка - это проблема артикуляции мысли о границах феномена поступка, выросшего из старорусского языка; русское слово, указывающие на феномен поступка, не имеет аналогов в других неславянских языках, не может быть адекватно переведено и должно транслироваться в соответствующей латинской транскрипции: «postupok». Все переводные аналоги русского слова затушевывают его суть, а, следовательно, и место философии поступка, феноменально естественной для русскоязычного сознания.

Благодаря мощной экзистенциальной интуиции М. М. Бахтина отечественная философия удерживает за собой позицию - владеющей ключом к единству первой философии (философии нравственности, философии жизни, философии опыта) и специальной философии (теоретической философии, философии слова) и знающей, как схватить феноменальную полноту поступка: бытие-событие доступно «изнутри его свершения в поступке».

М. М. Бахтин рассматривает феноменальную целостность поступка как событие, в котором различаются единство персонального и смыслового моментов поступка; единство свойств поступка (аксиологичность, ответственность, событийность, единственность); единство сил, порождающих поступок (сознание и эмоционально-волевой тон); разнообразие его форм (мысль, дело, переживание и др.); архитектоника ответственности, стягивающая в одно все моменты нравственного напряжения я-для-себя, другой-для-меня, я-для-другого [2].

Из сопоставления (без претензий на глубокое и окончательное аналитическое заключение) философии поступка М. М. Бахтина и философии опыта Ф. Анкерсмита как набросков к преодолению ограниченности теоретической философии становятся очевидными условия, при которых поступок, утверждающий всю правду события, жизни, потсупающего, и возвышенный исторический опыт как опыт восхождения к онтологической истине могут признаваться феноменологически идентичными. С одной стороны, возвышенный исторический опыт может казаться близким к такой форме поступка, как эстетическое видение М. М. Бахтина, но, с другой стороны, поступок - эстетическое видение - удерживается моментами активного вживания, объективизации и вненаходимости [2], а возвышенный исторический опыт настаивает на утрате собственной идентичности для встречи и узнавания себя с тем и в том, чем уже не являешься, суть этого опыта - отклик на глубинную травму-утрату чего-то там на уровне коллективного бессознательного без гарантий возврата к прежней идентичности [1]. М. М. Бахтин предупреждает, что пассивное вживание, растворение себя в созерцаемом, скорее, есть безответственный отказ от себя, признание своего бытия несущественным. Но если потеря собственного места в бытии, утрата идентич- 
ности становятся ответственным поступлением, то есть вживающийся «максимально активно и сполна реализует единственность своего места в бытие» [2, c. 19], то такое вживание признается ответственным поступлением, а, значит, интересующий нас опыт проигрывается как поступок. С точки зрения философии поступка, возвышенный исторический опыт при определенных условиях есть одна из форм поступка, в которой незавершенное прошлое - когда-то прерванное событие (начавшееся где-то там, до нашего пребывания в мире, но по ряду обстоятельств резонирующее с нами) ждет от нас своего завершения, как западня (ст-рус. «сто̆па») голодного духа не отпускает без особых усилий онтологического восхождения.

Утверждение философии поступка как актуального и современного мировоззрения ожидает глубоких методологических штудий. В этом направлении видится полезным испытание «поступка» разнообразными феноменологическими процедурами, разработанными в западной философии. Например, в логике феноменологического метода М. Хайдеггера акцентировать внимание на действительном бытии поступка, высветить поступок как способ быть и как событие. Превзойти онтическое содержание феномена поступка и указать на онтологические корни, условия возможности многообразия форм и содержаний поступка в логике единства процедур редукции, конструкции и деструкции. К слову «поступок» применима и феноменологическая процедура деконструкции Ж. Деррида со всеми своими операциями, провоцирующая поиск не бинарных оппозиций, слагающих его феноменальную целостность. Здесь возможны провокации сути поступка его антиподом - проступком, для утверждения сомнения в очевидности его нравственного бытия; замена понятия поступка как личностного акта на безличностный акт и пр. Сам свершающийся поступок близок к логике процедуры деконструкции: его можно означить как деконструирующее (рас-страивающее и восполняющее) деконструируемого (наличествующего в качестве человеческого существа). К сожалению, методологическая рефлексия выходит за рамки данной статьи, но ее необходимость для организации ряда феноменологических процедур, вскрывающих сущностный ресурс поступка в качестве предмета философии, становится очевидной.

Подведем итоги:

- опираясь на тезис, что слово есть «метод концентрации» духа народа, можно констатировать, что суть самобытного славянского слова «поступок» нужно искать не в иностранных концепциях, посвященных его аналогу (И. Канта, Аристотеля), а отчасти в концепциях носителей языка (М. М. Бахтин) и на основе феноменологических процедур, вскрывающих его сущностную констелляцию во всем историзме его содержания и принципиально незавершенной сути;

- русское слово «поступок» отличается от его аналогов в других неславянских западных языках смысловым содержанием, потому не может быть адекватно переведено и должно транслироваться в соответствующей латинской транскрипции: «роstupok»;

- распаковка сакрального смысла слова «поступок» указывает на онтологическое основание поступка, воспринимаемое как ступа - ограниченность всякого человеческого бытия, одномоментно хранящая в себе необходимость снять эти ограничения; - событие выхода за границы ограничений. То есть возможность 
поступка покоится в стуnе, как удерживающей изменения и тем самым провоцирующей их;

- сущностный ресурс феномена поступка, запечатанный в слове «поступок» («посто̆пати», «посто̆пити», «посто̆пъ)), как предмет философской антропологии хранит дерзость к снятию противоречия между философией теоретической и философией опыта.

\section{Литература}

1. Анкерсмит Ф. Возвышенный исторический опыт. Москва: Европа, 2007. 612 с. Текст: непосредственный.

2. Бахтин М. М. К философии поступка // Собрание сочинений. Т. 1. Москва, 2003. С. 7-68. Текст: непосредственный.

3. Рубинштейн С. Л. Бытие и сознание. Человек и мир. Санкт-Петербург: Питер, 2003. 512 с. Текст: непосредственный.

4. Сагатовский В. Н. Русская идея: продолжим ли прерванный путь? // Хрестоматия по философии: учебное пособие / составители П. В. Алексеев, А. В. Панин. Изд. 2. Москва: Проспект, 2004. С. 540-571. Текст: непосредственный.

5. Сербско-хорватско-русский словарь. 54000 слов. Изд. 3, исправленное и дополненное / составитель И. И. Толстой. Москва: Советская энциклопедия, 1970. 736 с. Текст: непосредственный.

6. Срезневский И. И. Материалы для словаря древнерусского языка по письменным памятникам в 3 т. Т. 2. Л - П / Труд И. И. Срезневского. Санкт-Петербург: Отд-ние рус. яз. и словесн. Имп. АН, 1902. [3], 15 с., 1802 стб. URL: http://books.eheritage.ru/book/10075994 (дата обращения: 27.03.2020). Текст: электронный.

7. Срезневский И. И. Материалы для словаря древнерусского языка по письменным памятникам в 3 т. Т. 3. [РСрезневского. Санкт-Петербург: Отд-ние рус. яз. и словесн. Имп. АН, 1903. [1] с., 1684, 272 стб., 13 c. URL: http://books.e-heritage.ru/book/10075993 (дата обращения: 27.03.2020) Текст: электронный.

8. Чешско-русский словарь / редактор А. И. Павлович. Москва: Советская энциклопедия, 1967. Изд. 5, исправленное и дополненное. $845 \mathrm{c}$.

9. Флоренский П. А. У водоразделов мысли // Собрание сочинений: в 2 т. Т. 2. Москва: Правда, 1990. Текст: непосредственный.

10. Эпштейн М. Н. Поступок и происшествие. К теории судьбы // Вопросы философии. 2000. № 9. С. 65-77. Текст: непосредственный.

11. Kant Immanuel. Grundlegung zur Metaphysik der Sitten, hg. von Jens Timmermann, Göttingen: Vandenhoeck \& Ruprecht, 2004. .

12. Wielki słownik polsko-rosyjski: około 75,000 hasel. Warszawa; Moskwa: Wiedza Powszechna, 1967, 1344 c.

Статья поступила в редакиию 19.07.2021; одобрена после рещензирования 18.10.2021; принята к публикащии 15.11.2021. 


\section{PHENOMENOLOGICAL RESOURCE OF THE RUSSIAN WORD POSTUPOK 'AN ACTION'}

Olga I. Ilyina

Cand. Sci. (Philos.), A/Prof. of Psychology and Education Department, Far Eastern Federal University

10 Ayaks Lane, Vladivostok 690000, Russia

olilyina@bk.ru

Abstract. The article analyzes the originality of the Russian word postupok 'an action' based on the meanings identified in the logic of P. Florensky's trichotomous model of the word, and recorded in the texts of Slavic dictionaries, as well as in the materials for I. I. Sreznevsky's Dictionary of the Old Russian language. This methodological maneuver made it possible to argue the position that the ontological basis of postupok "an action' must be sought in stupa - the limitation and incompleteness of the moment, existance, consciousness, which at the same time involve the need to overcome these limitations. We should seek for the phenomenological resource of the Slavic word postupok 'an action' not in the foreign concepts (I. Kant, Aristotle, etc.) devoted to its analog, but in the concepts of native speakers (M. M. Bakhtin, V. N. Sagatovsky and others), and on the basis of phenomenological procedures that reveal its content, structure, fundamental incompleteness of the essence. We should also point to the prospects of phenomenological studies in the field of philosophy of an action as opposed to the dictates of philosophy of theories and language, if both the semantic content of the phenomenon of an action in the word and the idea of modifying the multilevelness of human being in an action are taken into account.

Keywords: postupok 'an action', originality, word, semantic content, co-existence, multilevel, ontological basis, phenomenon, phenomenological procedures.

\section{For citation}

Ilyina O. I. Phenomenological Resource of the Russian Word postupok 'an action'. Bulletin of Buryat State University. Philosophy. 2021; 4: 53-61.

The article was submitted 19.07.2021; approved after reviewing 18.10.2021; accepted for publication 15.11.2021. 